\title{
Os laços sociais afetivos como ponto de inflexão e possibilidade de prevenção às práticas delituosas
}

\author{
Affective social ties as an inflection point and possibility of \\ preventing criminal practices
}

Los lazos sociales afectivos como punto de inflexión y
posibilidad de prevención de prácticas delictivas

Recebido em 19-08-2020

Modificado em 13-12-2020

Aceito para publicação em 07-02-2021

\section{Gusthavo Ribeiro Bacellar}

Graduado em Ciências Sociais pela Universidade Federal do Espírito Santo (UFES), Brasil e em Direito pela Universidade Federal da Bahia (UFBA), Brasil. Mestre em Ciências Sociais pela Universidade Federal do Espírito Santo (UFES). Promotor de Justiça do Ministério Público do Espírito Santo, Piúma, Brasil. E-mail: gusthavobacellar@hotmail.com

\section{Resumo}

O presente trabalho tem por objetivo analisar achados que indiquem a influência do fortalecimento de vínculos familiares, especialmente o casamento/união estável e o nascimento/convívio com filhos, para a interrupção da prática de delitos, utilizando como metodologia a realização de entrevistas semiestruturadas com egressos do sistema prisional, condenados por crimes patrimoniais ou tráfico de drogas. Valendo-se de uma perspectiva interacionista e trabalhando os conceitos de ponto de inflexão e desistência colateral de Laub e Sampson (2003), a pesquisa realizada verifica como a maior integração em sistemas sociais como a família favorece o afastamento de práticas ilícitas.

Palavras-chave: família; controle social; desistência; crime. 


\section{Introdução}

O campo de estudos da sociologia do controle social historicamente tem apontado caminhos epistemológicos e estudos empíricos que buscam compreender os fatores que levam o indivíduo a interromper a prática criminal, a partir de uma perspectiva interacionista, como fazem crer os estudos de Agnew (1991), White (1992), Horney (1995), Jungers-Tas (1992); Paternoster e Mazerolle (1994).

Isso porque a maior ou menor inserção do indivíduo em sistemas sociais, conforme indica esse campo teórico, se relaciona diretamente com o afastamento ou a permanência em atividades ilícitas, surgindo o estabelecimento de vínculos afetivos com uma parceira e o nascimento de filhos, como possibilidade de novas perspectivas de vida dos envolvidos em atos ilícitos, conforme foi possível perceber em nossa pesquisa.

Para tanto, a pesquisa utilizou como metodologia a seguinte abordagem: entre dezembro de 2018 e fevereiro de 2019, realizamos 14 (catorze) entrevistas semiestruturadas com residentes no município de Piúma/ES e que haviam sido condenados por crimes patrimoniais ou tráfico de drogas, tendo permanecido presos em razão desses fatos, explorando suas histórias de vida e fatores que podem ter contribuído com o envolvimento em ilícitos ou com o afastamento dessas práticas. Nos meses de agosto e setembro de 2019, na Grande Vitória/ES, realizamos 13 (treze) entrevistas com pessoas de características semelhantes e residentes nesta região com o objetivo de realizar uma espécie de grupo de controle, sendo que os achados explorados neste artigo surgiram de forma bastante semelhante neste segundo momento, confirmando o que foi obtido na primeira etapa da pesquisa ${ }^{1}$.

$\mathrm{Na}$ primeira parte da pesquisa, realizada em Piúma/ES, os entrevistados foram convidados a participar das entrevistas ao comparecerem ao fórum para justificar suas atividades, obrigação imposta àqueles que cumpriam pena em regime aberto. Neste momento, recebiam abordagem do autor, promotor de justiça do município, que explicava os objetivos da pesquisa e os convidava a participar de uma entrevista, que ocorria no prédio da Promotoria de Justiça ao lado do fórum, em uma outra data combinada entre ambos.

Em razão do risco de que os relatos obtidos tenham sofrido a influência de aspectos como a profissão do entrevistador e consequente natureza da relação jurídica existente entre ele e o entrevistado, local da realização das entrevistas, entre outras contingências, conforme Goffman, segundo o qual a interação é “(...) a influência recíproca dos indivíduos sobre as ações uns dos outros, quando em presença física imediata. (...) Um ‘desempenho' pode ser definido como toda

\footnotetext{
${ }^{1}$ Com o fim de preservar suas identidades, os nomes utilizados neste artigo para os entrevistados são fictícios.
} 
atividade de um determinado participante, em dada ocasião, que sirva para influenciar, de algum modo, qualquer um dos outros participantes" (Goffman, 2014:28), foi sugerido ao autor a realização de um grupo de controle com o objetivo de comparar os achados obtidos.

Assim, realizamos mais 13 (treze) entrevistas com um público semelhante e residente na Grande Vitória/ES. As entrevistas ocorreram no prédio onde funciona o Escritório Social da Secretaria de Justiça, que atende os condenados residentes na Grande Vitória/ES e que cumprem pena em regime aberto. Os entrevistados eram abordados no momento que encerravam o atendimento para comprovação dos comparecimentos mensais, sendo explicados os objetivos da pesquisa e convidados para participar de uma entrevista, que ocorria em seguida em uma das salas do prédio. Os entrevistados não tiveram conhecimento da ocupação profissional do entrevistador, que apenas se identificou como pesquisador.

Nos resultados encontrados a partir das narrativas obtidas, cujo uso para este trabalho se limitou aos achados confirmados no grupo de controle, surgiu de forma significativa a relação entre o casamento/constituição de união estável/nascimento de filhos e a interrupção da prática de crimes, assim como foi comum o relato do retorno às atividades criminais com a separação e a redução do convívio com os filhos.

Neste trabalho, então, nos propusemos descrever os trechos mais significativos dos relatos obtidos junto aos entrevistados e analisá-los à luz de marcos teóricos da sociologia do controle social, tentando compreender como a maior integração em sistemas sociais favorece a interrupção das práticas ilícitas, a partir das noções de ponto de inflexão e desistência colateral, de Laub e Sampson (2003).

\section{A influência da família na interrupção da prática de ilícitos}

Conforme será debatido neste tópico, na pesquisa realizada constatou-se que o casamento ou a constituição de união estável, bem como o nascimento de filhos, se configurou como fatores significativos para a mudança de vida dos grupos pesquisados. Vários entrevistados haviam tido filhos recentemente ou possuíam esposa/companheira que estava grávida, o que era um forte fator, em seus relatos, para justificar a decisão de mudança, deixando as práticas ilícitas e passando para uma vida de dedicação ao trabalho lícito e à família

De acordo com Polakowski:

(...) a resposta, para Hirschi, foi que os processos de socialização iniciados na família e estendidos a outras instituições sociais fomentam o vínculo do indivíduo com a sociedade, constituído pelos elementos de apego, compromisso, envolvimento e crença na ordem moral convencional (Polakowski, 1994:43 [tradução nossa]). 
Dentre os 14 (catorze) entrevistados residentes em Piúma/ES, 11 (onze) indicaram, em seus relatos, que a família se constituiu em um relevante fator de controle social, contribuindo para afastá-los das práticas ilícitas, assim como em 06 (seis) destes entrevistados fatores como o divórcio ou o fim da união estável, e a consequente diminuição do convívio com filhos, levaram ao retorno às práticas ilícitas.

Foi possível perceber das pesquisas que alterações estruturais e circunstanciais podem impactar nas mudanças de vida, sendo relevantes para compreender tal processo os conceitos de ponto de inflexão e desistência colateral.

O ponto de inflexão se constitui em uma mudança de rota na trajetória do indivíduo, sendo exemplos deste processo obtidos na pesquisa o casamento/união estável e o nascimento do filho. A noção de desistência colateral, por sua vez, indica que este processo de mudança decorre, de forma predominante, de alterações estruturais no entorno do indivíduo, e não propriamente de uma decisão voluntária e consciente do agente.

Algumas entrevistas realizadas são especialmente interessantes para vislumbrar essas lógicas, iniciando com os relatos dos entrevistados residentes em Piúma/ES, a exemplo de Teotônio, que afirmou o seguinte sobre suas razões para deixar o crime:

(...) os caras que eu pegava a droga pra mim vender, no passado, eles me ofereceram, eu falei 'não, to querendo voltar pra minha esposa de novo. Quero ter minha filha, meus filhos perto de mim, quero ter minha família do meu lado. Quero mexer com nada.' Aí, pode até ver, martelada no dedo, eu to dando. Viver naquela vida do passado eu não vou querer não.

Perguntado sobre a motivação para buscar emprego lícito, Teotônio respondeu que “(...) foi intenção da Jéssica (sua companheira), pediu pra mim ficar trabalhando" (Trecho de entrevista concedida por Teotônio, Piúma/ES, 20/02/19), constituindo-se o início deste relacionamento em um ponto de inflexão em sua trajetória de vida, que naquele momento se encontrava impregnada de práticas ilícitas, especialmente o tráfico de drogas.

Também interessante é a história de Genilson, que relatou que em 2016 decidiu parar de comercializar substâncias psicoativas ilícitas ao conhecer sua filha: “(...) aí eu decidi parar mesmo. Que aí eu conheci minha filha. Eu tenho uma filha de quatro anos, fui preso a mãe dela tava grávida na época" (Trecho de entrevista concedida por Genilson, Piúma/ES, 13/12/18).

O entrevistado Anderson, que compartilhou em sua entrevista sua difícil e sofrida história de vida, disse sobre o dilema que passou ao ver o corpo de seu irmão logo após ser assassinado:

Aí dali eu botei ódio, falei 'tenho que vingar meu irmão, né', não vou mentir pro senhor, to falando a verdade. Aí 'tenho que vingar meu irmão, vou matar eles', aí no momento ali, vendo meu irmão ali com vários tiros, né, na cara. Os dois olhos dele com bala, né, na boca, na cara. Olhava pra ele assim, não saía lágrima. Às vezes vinha uma pessoa falar comigo, eu ignorava, não queria conversa (...) e comecei a pensar coisas 
erradas, né, de vingança, de entrar no crime e fazer pior, né, e cobrar deles. E às vezes eu pensava assim, 'não, eu vou cuidar da minha filha, vou cuidar da minha família', e foi onde eu botei na minha cabeça 'não, vou cuidar da minha filha, vou cuidar da minha família'. Minha filha precisa de mim, se eu matar esses caras, eu vou piorar mais a minha vida, porque eu vou prejudicar a minha vida na Justiça, eles vão morrer, mas eu não vou viver a minha vida. Eu vou me matar na cadeia, eu vou viver minha vida na cadeia. Não vou ver minha filha crescer, não vou tá junto com a minha esposa, né. (Trecho de entrevista concedida por Anderson, Piúma/ES, 17/01/19).

E sobre o momento em que concedeu a entrevista, quando estaria afastado das práticas ilícitas, disse que “(...) hoje não, hoje depois que eu conheci essa mulher aí, minha vida mudou completamente. Eu vivo pra mim e pra ela, entendeu?" (Trecho de entrevista concedida por Anderson, Piúma/ES, 17/01/19).

Roberto, contando sua trajetória de vida de envolvimento em roubos e comércio de substâncias psicoativas ilícitas, narrou um breve período em que esteve afastado destas práticas: “(...) Ela (sua então companheira) me ajudou em muita raça de coisas. Por ela eu parei de usar drogas, só estava estudando mesmo. Tranquilo. A mãe dela deu uma casa, nós fomos morar lá, saímos do aluguel. Esses quatro anos foi só trabalho, lazer com os filhos dela (...)" (Trecho de entrevista concedida por Roberto, Piúma/ES, 06/02/19).

Tião traz o relato de que não teve envolvimento no crime pelo qual foi condenado e, por revolta e devido ao aprendizado social da prisão, passou a traficar, somente parando ao conhecer sua companheira: “(...) logo eu conheci minha mulher, aí parei com isso (tráfico), ela não aceitava (...)" (Trecho de entrevista a mim concedida por Tião, Piúma/ES, 23/01/19).

Sílvio, ao ser perguntado sobre quais fatores o fariam se afastar das práticas ilícitas em que se envolveu, afirmou: "Família, né! Família, família pra mim é tudo. Meus filhos, que tá vindo agora nenenzinho aí, já tenho uma filha, né, igual falei pro senhor, e agora tá vindo um menino. Até o dia seis ele tá aí, em nome de Jesus (...)” (Trecho de entrevista concedida por Sílvio, Piúma/ES, 30/01/19).

O entrevistado José Antônio também relatou essa lógica. Ao ser perguntado o que faria com que decidisse sair da vida de ilícitos que vinha levando, respondeu que era medo “(...) de não morrer e não ver minha filha crescer. E minha mãe também, né. Tem que dar também um sossego pra ela".

Questionado sobre a importância da família para uma mudança de vida, respondeu:

(...) porque assim, não é só o cara que sofre. Mas sim também a família também sofre. E você vê que eles estão demonstrando que eles estão sofrendo mesmo de verdade, quando é falsidade você também reconhece, mas quando é de verdade... tem que falar “não, chega. Basta!” Que nem minha mãe, minha mãe, por, devida das vezes ali, ligava pra lá, chorando "meu filho, vem pra cá, meu filho. Eu preciso te ver, que eles vão te matar nesse lugar aí. A honra de Deus é os pais morrer primeiro que os filhos, por favor, meu filho!" Aí ali, aquelas palavras "foi" tocando, né, focalizando dentro da minha 
memória. Falei "chega!", botei o pé no chão, falei "chega. Chega. Basta" (Trecho de entrevista concedida por José Antônio, Piúma/ES, 13/02/19).

O entrevistado Edvaldo também relatou a importância da presença de seus pais para se afastar da vida de ilícitos e iniciar uma rotina regular, de atividades legais e não desviantes:

Às vezes ele falava (seu pai): "o que eu estou fazendo, meu filho? O que está faltando para você, para você ser assim?” Então, aquilo ali sempre foi entrando na minha cabeça. Poxa, ele faz tudo que eu peço. Se preciso de uma sandália , tá na mão. Olhava aquilo ali e via minha mãe triste só por mim. E os outros dava alegria a ela. Aí eu falei: "não, vou mudar isso!" (...) Ela (sua mãe) sempre ficava triste, sempre ficava triste pelo canto. Hoje em dia eu vejo alegria na minha mãe. Minha mãe não fica mais pelo canto chorando. (Trecho de entrevista concedida por Edvaldo, Piúma/ES, 24/01/19).

No grupo de controle realizado com residentes na Grande Vitória/ES, tais achados foram confirmados e surgiram de forma semelhante, a exemplo da fala de Alberto que, ao ser perguntado o que de fato muda o indivíduo, respondeu que, com ele, foi “(...) a questão de ter minha família." Sobre o tempo que passou na prisão, relatou que:

(...) se o cara ver a falta da família que tem, a falta de mulher, que se a pessoa for casada ou não, se não for visitar ele, aí ele vai sentir falta. (...) Vai olhar e falar "po, será que... vale a pena eu tá fazendo o que tô, pra ficar aqui preso no meio de um monte de homem mostrando bunda pra gente. Será que vale a pena?” (...) Aí depois eu fui vendo que infelizmente a gente tinha que passar por aquilo dali pra gente ver. E se eu não passasse por aquilo dali, se eu não ficasse preso aquele tempo ali, eu não ia ter o valor da minha família. (Trecho de entrevista concedida por Alberto, Vitória/ES, 09/08/19).

Galdino, também do grupo de controle, questionado sobre o que pesa mais para a pessoa sair da condição da prática de ilícitos, afirmou: “A família!”. Em continuidade, explicou:

[...] é doído demais você tá lá preso, tipo, às vezes eles te encaminham pra uma cadeia longe, aí a sua mãe tem que trabalhar e te visitar! Às vezes ela deixa de ir trabalhar pra poder ir te visitar e às vezes ela vai e te visita quinze minutinhos. Na cadeia de maior, igual, é no acrílico, pega o telefonezinho, fica quinze minutinhos, depois se despede, pode dar nem um abraço. Isso é doído, lá dentro. (Trecho de entrevista concedida por Galdino, Vitória/ES, 30/08/19).

Renato, que no momento da entrevista se encontrava casado, com filhos e afastado do cometimento de tráfico e roubo, crimes pelos quais fora condenado e passou certo período preso, respondeu da seguinte forma ao ser perguntado sobre os motivos pelos quais parou de usar maconha, apesar de gostar:

Eu não uso porque hoje eu sou casado, tenho filhos, entendeu? E eu tenho essa responsabilidade dos meus filhos. Eu gosto! Se fosse usar, eu usava mesmo, mas eu não uso por causa disso, entendeu? Tenho minhas responsabilidades, tenho o meu trabalho. Então eu primeiro enxergo isso, entendeu? Vejo isso. Por que antes eu não tinha essa mentalidade, entendeu, de hoje. Então é isso aí. Mas maconha atrapalha sim. Atrapalha sim. Qualquer droga atrapalha, qualquer droga, até cigarro. (Trecho de entrevista concedida por Renato, Vitória/ES, 13/09/19). 
Josué, do grupo de controle, afirmou que parou de ingerir álcool e fumar maconha “(...) pelo fato do meu filho, pra não feder, não pegar no meu filho, não ficar fedendo droga, então eu consegui parar”. (trecho de entrevista concedida por Josué, Piúma/ES, 13/09/19).

Em outro momento da entrevista destacou como aspecto negativo da prisão:

(...) trabalho familiar. Trabalho da família. Pra ir, ou até mesmo algumas vezes passar por situações desagradáveis (na revista), entendeu? (...) Aí às vezes a família passava por isso, aí falava: "ah, a gente não quer mais isso" e tal, "sai daqui, melhora". E, assim, o sofrimento da família é grande. (...) Porque a família não quer ver você ali dentro. (Trecho de entrevista concedida por Josué, Piúma/ES, 13/09/19).

E, perguntado sobre o que realmente pesa para a mudança de vida, respondeu que, em seu caso, além do sofrimento da família enquanto esteve preso, foi "[...] o sonho de ter o meu garotinho com a minha esposa." (trecho de entrevista concedida por Josué, Vitória/ES, 13/09/19).

Essas entrevistas do grupo de controle indicaram, então, a importância dos vínculos familiares para a interrupção de uma carreira desviante, mesmo que seja através do sofrimento gerado ao indivíduo e sua família com a prisão ou referente apenas ao uso de drogas.

Julio, ao responder a mesma pergunta sobre fatores importantes para uma mudança de vida, disse:

(...) agora, tipo assim, eu penso diferente, né, porque antes eu não pensava. Agora eu penso diferente, graças a Deus. Agora eu coloquei a cabeça no lugar, né. Eu vi que isso daí não é pra mim. Aí eu... eu pensei diferente, quando você fala, agora eu tô com vinte e oito anos, parece que você para, assim "não, eu não vou mais mexer com nada disso aí", aí depois você dá aquele basta. depois que você arruma mulher direita, entendeu? A mulher tá ali, tá ajudando ali, entendeu? (...) ter mulher, quando se arruma mulher, uma pessoa, uma companheira, ela te ajuda, te ajuda a você sair daquela vida. Entendeu? Quando o cara tá sozinho, ele começa a fazer merda. Quando a pessoa tem uma companheira e tá ali do lado dele, pra ajudar ele, pra qualquer coisa, pra ajudar ele. Tá ali, entendeu, dando um conselho a ele, entendeu? Assim que é bom. Quando a pessoa tá sozinha, parece que fica assim, com o inimigo, assim. Vem sempre um pra poder querer te perturbar com alguém. (...) Aí depois que eu arrumei essa companheira, eu consegui. Que eu consegui mudar. Foi por causa dela que eu resolvi mudar, que hoje eu tô bem até hoje. Eu consegui parar com tudo, graças a Deus. (Trecho de entrevista concedida por Julio, Vitória/ES, 16/08/19).

Cristóvão, condenado e preso por roubo e tráfico, atribuiu ao fato de ter se afastado de sua mãe, cujo convívio perdeu ao mudar do interior da Bahia para a região metropolitana do Espírito Santo, seu envolvimento em ilícitos. Falou que sua mãe “(...) fez muita falta.”, que ela estava “(...) sempre falando, dando conselho (...)", concluindo que se não tivesse saído de perto de sua mãe nada do que ocorreu com ele teria acontecido (Trecho de entrevista concedida por Cristóvão, Vitória/ES, 30/08/19).

Ainda no grupo de controle, Guilherme, ao ser questionado sobre o que é mais importante para a pessoa não voltar a praticar ilícitos, respondeu: “(...) é a família, né. Família da gente” (Trecho de entrevista concedida por Guilherme, Vitória/ES, 23/08/19). 
De acordo com Shapland e Bottons:

\begin{abstract}
A primeira é que aqueles que vinham cometendo delitos às vezes entram em contato com novas pessoas e/ou novos contextos sociais (por exemplo, um parceiro romântico, um trabalho realmente interessante ou uma comunidade religiosa) onde encontram normas sociais novas e atrativas. Gradualmente, essas novas normas e interesses tornam-se cada vez mais centrais para a vida da pessoa. (Shapland; Bottons, 2017:751 [tradução nossa]).
\end{abstract}

Freitas percebeu que, enquanto um dos jovens que pesquisou “(...) permaneceu com um núcleo familiar mais coeso, sentia que não havia qualquer necessidade de iniciar uma carreira criminal" (Freitas, 2019:182), o que pôde ser percebido nos relatos da grande maioria dos entrevistados, em que o estreitamento de vínculos familiares, como o casamento, o nascimento de filhos, a presença do pai e da mãe etc., se constituiu em fator extremamente relevante para a interrupção da prática de ilícitos e a mudança de vida.

E o ponto é exatamente que a maior integração no sistema social favorece esta interrupção, conforme Junger-Tas:

A ideia principal é que aqueles que têm boa relações com os pais e outras pessoas significativas, que têm um bom desempenho na escola, no local de trabalho e em clubes de esportes ou de jovens, que estão comprometidos para metas futuras convencionais, e que apóiam ideais conformistas, normas e os valores têm muito a perder com comportamentos desviantes. A maioria deles não vai correr esse risco. Esses elementos foram reunidos em uma teoria consistente por Hirschi (1969), afirmando que quanto mais vínculos uma pessoa tem com a sociedade, menos ele estará inclinado a transgredir as normas legais e cometer atos delinquente (Junger-Tas, 1992:10 [Tradução nossa]).

Assim como são múltiplos e variados os fatores que levam o indivíduo ao cometimento de crime, é complexo precisar o motivo que leva à interrupção da prática criminal. Mudanças estruturais e de contextos, entretanto, surgem como questões determinantes nesses processos de mudança, destacando-se a noção de ponto de inflexão nesta análise.

Um ponto de inflexão na vida de um indivíduo envolvido em ilícitos significa uma virada no rumo de sua vida, constituindo-se o casamento/união estável uma ocorrência importante neste processo e que, nas histórias narradas, se destacou, juntamente com o nascimento do filho, como um importante fator a levar o envolvido em crimes a se afastar dessas práticas.

A teoria de Laub e Sampson enfatiza a “(...) a importância dos laços sociais em todas as idades ao longo da vida. O princípio organizador era que é mais provável que o crime e o desvio ocorram quando o vínculo de um indivíduo com a sociedade é fraco ou quebrado" (Laub; Sampson, 2003:6 [Tradução nossa]).

Estes autores ressaltam a importância de controles sociais informais que decorrem de trocas sociais e do estabelecimento de vínculos interpessoais, concluindo que pontos de inflexão 
relacionados ao encontro de um parceiro e à constituição de família são determinantes para o abandono de uma contingência de práticas ilícitas.

Laub e Sampson constatam que a interrupção não ocorre de forma abrupta, sendo, em verdade, uma mudança gradual, que envolve, com frequência, neste processo, a descoberta de um parceiro afetivo que passa a exercer um controle social informal sobre o agente, o que também ocorre de maneira gradativa. Segundo os autores, “(...) o casamento pode levar à desistência por causa dos efeitos diretos do controle social dos cônjuges" (Laub; Sampson, 2003:136 [Tradução nossa]).

As esposas/companheiras, em alguns dos casos estudados, assumiram o controle da vida dos maridos/companheiros, exigindo que adotem um estilo de vida diverso, a exemplo dos casos de Tião e Teotônio, que abandonaram o comércio ilícito de substâncias psicoativas em razão da postura firme de suas parceiras de não aceitar estas práticas.

Assim como para alguns a mulher assumia a função de 'chefe', coordenando e gerenciando a vida do companheiro, para outros a mudança de vida proporcionada pelo casamento se dava em razão da parceira suprir uma demanda afetiva e de atenção nunca recebida. Muitos entrevistados cresceram em ambientes de forte tensão familiar, onde a prática da violência era uma constante, possuindo a parceira um sentido afetivo especialmente relevante face a uma história de vida de déficit de cuidado e afeto, a exemplo da história de vida de Anderson, que apanhava constantemente do pai caso chegasse em casa sem comida e via com frequência sua mãe ser agredida pelo genitor em razão do uso abusivo de álcool.

A redução do envolvimento em ilícitos em paralelo ao casamento ou à constituição de união estável também pode ser compreendido a partir da noção de associação diferencial, que significa a prevalência, dentro daquele contexto habitado pelo indivíduo, de determinadas opiniões em detrimento de outras.

No caso do casamento/união estável o agente tem reduzido drasticamente o tempo que passa com amigos, gastando a maior parte de seu tempo convivendo com sua companheira e envolvido na nova rotina estabelecida a partir do novo relacionamento afetivo, o que também inclui o convívio com familiares e amigos de sua parceira. Conforme Laub e Sampson, referindo-se a um dos casos que estudou, “(...) seus parentes por afinidade o 'cercaram' e o adotaram em suas famílias” (Laub; Sampson, 2003:137 [Tradução nossa]).

Para Matsueda:

Definições favoráveis e desfavoráveis (padrões de comportamento) são ponderadas por frequência, duração, prioridade e intensidade. Assim, os padrões de comportamento apresentados com maior frequência, apresentados por mais tempo, apresentados mais precocemente na vida, e apresentados por uma fonte de maior prestígio, terão mais peso 
no processo produzindo comportamento delinqüente ou não-delinquente (associação diferencial) (Matsueda, 1982:489 [tradução nossa]).

A noção de associação diferencial nos auxilia a compreender, então, por que o casamento/união estável pode contribuir com a redução do envolvimento do indivíduo em crimes. Ao estar menos exposto a opiniões favoráveis a comportamentos criminais, e em contato mais frequente com opiniões contrárias às práticas ilícitas, o agente tende a escassear seu cometimento de crimes, o que também ocorre em paralelo à redução das oportunidades de desviar. A mudança na rotina do agente é também crucial para a alteração de sua dinâmica de vida.

Essa nova rotina estrutura a vida do agente e cria vínculos emocionais, a exemplo da necessidade de desenvolver um trabalho lícito que permita o sustento do lar. $\mathrm{O}$ compartilhamento de um novo conjunto de valores pode afastá-lo gradativamente de atividades ilícitas e o levar para trabalhos aceitos e valorizados pelo grupo ao qual passa a fazer parte.

Além disso, a série de atividades de sua nova rotina tende a ocupar a maior parte de seu tempo e reduzir as oportunidades para o envolvimento em ilícitos. Citando o casamento como um importante ponto de inflexão no processo de interrupção criminal, Laub e Sampson percebem que ele cria novas situações que

(1) separam o passado do presente; (2) fornecem não apenas supervisão e monitoramento, mas oportunidades de apoio e crescimento social; (3) trazem mudanças e estrutura às atividades rotineiras; e (4) fornecem uma oportunidade para transformação de identidade. (2003, p. 148)

Primeiro, o casamento oferece os recursos potenciais de outra pessoa (suporte social e capital). Presumivelmente, à medida que o casamento continua, esses investimentos crescem com o tempo e se fortalecem. Segundo, o casamento contém um elemento de controle social direto. Os cônjuges costumam monitorar e supervisionar seus companheiros em relação a uma variedade de comportamentos, incluindo crime e desvio. As estratégias adotadas pelos cônjuges variam de 'tolerância zero' a 'gerenciamento e contenção', mas a intenção é a mesma - controle social informal. Terceiro, o casamento significa uma mudança nas atividades de rotinas e estilos de vida, a saber, novos amigos, nova família e novas obrigações. Rotinas anteriores podem não ser mais possíveis devido a demandas e obrigações concorrentes. Quarto, o casamento geralmente significa uma mudança residencial, que pode afetar as atividades rotineiras e, por sua vez, influenciar as oportunidades e as barreiras ao crime. Quinto, o casamento pode levar a filhos, que não apenas podem mudar a visão de mundo, mas também alterar drasticamente as atividades rotineiras (Laub; Sampson, 2003:283 [Tradução nossa]).

Um relacionamento afetivo pode se constituir, então, em um ponto de inflexão que induz mudanças estruturais e catalisa alterações comportamentais de longo prazo. É a alteração no contexto e nas circunstâncias de vida, mais do que o poder da agência, que em alguma medida existe, ou eventual percepção do erro das condutas praticadas e arrependimento, que pode levar à interrupção das práticas criminais. Conforme Becker, "Uma explicação estrutural da mudança 
pessoal tem implicações importantes para as tentativas de moldar deliberadamente 0 comportamento humano" (Becker, 1964:52 [Tradução nossa]).

Para Laub e Sampson:

À medida que o investimento em títulos sociais cresce, o incentivo para evitar aumenta, porque mais está em jogo. Nossa posição anterior foi a de que os laços sociais no casamento são importantes na medida em que criam sistemas interdependentes de obrigação e restrição que impõem custos significativos para a conversão de propensões criminais em ação (Laub; Sampson, 2003:42 [Tradução nossa]).

Assim, a medida em que tais laços são construídos, o agente tende a perceber que tem 'mais a perder' com a prática de delitos, aprendendo os requisitos para manter aquela nova situação. De acordo com Becker, "Se ele tem um forte desejo de continuar, a capacidade de avaliar com precisão o que é necessário, e pode entregar o desempenho exigido, o indivíduo se transforma no tipo de pessoa que a situação exige.” (Becker, 1964:52 [Tradução nossa]).

Além disso, o casamento/união estável pode dar ao agente um novo status de seriedade, compromisso e reponsabilidade. Sobre essa questão, vale citar o seguinte trecho da entrevista de Renato a respeito da decisão de parar de usar maconha:

\footnotetext{
Vou falar uma verdade, maconha não faz... Não sei se faz mal, eu vou falar a verdade, eu gosto de maconha. Eu não uso porque hoje eu sou casado, tenho filhos, entendeu? E eu tenho essa responsabilidade dos meus filhos. Eu gosto! Se fosse usar, eu usava mesmo, mas eu não uso por causa disso, entendeu? Tenho minhas responsabilidades, tenho o meu trabalho. Então eu primeiro enxergo isso, entendeu? Vejo isso. Por que antes eu não tinha essa mentalidade, entendeu, de hoje. (Trecho de entrevista a mim concedida por Renato, Vitória/ES, 13/09/19).
}

Esse novo status que é assumido pelo indivíduo depois que casa pode contribuir, também, para o abandono daquela pregressa vida de desvios.

Nesse contexto, o nascimento de filhos assume também uma elevada importância, podendo contribuir para o ingresso nesse novo status de seriedade e responsabilidade e nessa transição para uma condição de vida mais estável.

Laub e Sampson utilizam a noção de desistência colateral para explicar que este processo com frequência ocorre menos em decorrência da própria agência e mais em razão de mudanças estruturais e conjunturais que gradativamente levam o indivíduo a abandonar as práticas ilícitas e iniciar uma trajetória distinta. De acordo com os autores a interrupção “(...) para nossos sujeitos não era necessariamente um processo consciente ou deliberado, mas a consequência do que Howard Becker chama de 'apostas paralelas' (1960, 38)” (Laub; Sampson, 2003:278 [Tradução nossa]). 
Assim como a interrupção das práticas ilícitas podem decorrer de mudanças estruturais no contexto de vida do agente, abalos e rupturas situacionais, conforme pôde ser percebido em nossa pesquisa, podem gerar retrocessos e o retorno ao cometimento de ilícitos.

Conforme relatos de diversos entrevistados, a separação da mulher e o afastamento dos filhos se constituiu em um forte fator para uma recaída e retorno para o uso de drogas e prática de crimes, a exemplo de Fabiano, condenado por roubo. Ao ser questionado sobre os principais fatores que podem ter contribuído com sua trajetória de vida, respondeu:

O principal fator, pra mim, foi ter perdido a minha família. O direito de encontrar meus filhos na escola. De levar. Que eu ia em reunião de pais. Eu via meus filhos dormirem. Eu perdi minha família. (...) Meus filhos tem uma visão de pai muito errada de mim. E eu não sou esse tipo de pessoa. Aí isso pra mim foi a gota d'água. Aí passou uns negócios na minha cabeça, se eu morrer, amanhã faz um dia, dois dias. Se for preso, to nem aí! Comecei a desgostar um pouco da vida. Aí isso me levou a... a piorar mais ainda o meu estado. (Trecho de entrevista a mim concedida por Fabiano, Piúma/ES, 21/02/19)

Teotônio, ao ser questionado se, mesmo quando terminou um determinado relacionamento anterior, conseguiu manter a decisão de mudar de vida, respondeu negativamente, afirmando que sua cabeça “(...) bagunçou, eu vim embora pra Piúma e eu me envolvi de novo no tráfico" (trecho de entrevista concedida por Teotônio, Piúma/ES, 20/02/19).

Em seguida relatou sobre a situação que estava vivendo no momento da entrevista:

(...) aí de lá pra cá, só trabalhando, trabalhando e tamos aí trabalhando aí ainda. Tô pegando obra, fiquei esses dias, semana parado, mas correndo atrás aí, conseguir outro emprego. Mas só que aí agora, nesse caso, tem cinco mês que nós tão separado, hoje tá fazendo cinco mês que nós tão separado. Esses cinco mês pra mim, eu trabalho um dia na semana, dois dias, três dias, porque eu não tô tendo muita cabeça pra mim trabalhar, perco noite de sono. Já várias gente me dando oportunidade, assim, tá oferecendo droga pra voltar vender de novo, mas eu to querendo ter a minha vida com a minha família, tá trabalhando. Arrumar um serviço de carteira assinada. porque minha família pra mim é tudo do meu lado. Eles que estão me segurando pra mim não cair na vida do tráfico de novo. Na vida errada. De tanto ela tá me segurando, tá falando pra mim sair do tráfico, viver a vida melhor pra nós trabalhar, pra mim trabalhar, aí agora do nada separar de mim. (Trecho de entrevista a mim concedida por Teotônio, Piúma/ES, 20/02/19).

A trajetória de Teotônio é muito clara a respeito da forte relação entre o fortalecimento de vínculos familiares, no caso constituição de união estável e nascimento de filhos, e a interrupção da prática de crimes, tendo retornado ou estando prestes a retornar, no momento da entrevista, ao cometimento de ilícitos após a separação e o afastamento dos filhos.

José Antônio também traz relatos a respeito da relação entre separação e retorno para o crime:

(...) que nem eu, esse um ano e um mês que eu tava lá, que eu caí lá dentro, eu falei 'não, Senhor, eu sei que eu to aqui forjado', comecei a entrar na presença de Deus, peguei a Palavra lá, lá dentro... desse presídio aqui de Marataízes. Levei a Palavra de Deus lá dentro. Saí, mas, chegou aqui a minha mente, ela... quando eu vi aquela foto lá eu falei 'meu Deus!', a foto da Carol, com um cara, com a minha filha do lado, eu falei 
'Meu Deus!' Aí dali nebriou minha mente. Falei ‘vou fazer isso! Não sei o que lá, não sei o quê!' dali mesmo... já fui pro outro lado. Foi nessa que aconteceu isso tudo. Mas tudo é obra de Deus. (Trecho de entrevista concedida por José Antônio, Piúma/ES, $13 / 02 / 19)$.

Roberto também nos indica a relação entre desfazimento de vínculos familiares e retorno a uma vida de ilícitos. Ao ser perguntado como se deu o início de seu envolvimento com o tráfico de drogas, afirmou:

Nós separamos e aí eu comecei a usar droga de novo. Fui morar com um amigo meu, perto ali também. Aí, depois, logo em seguida eu já aluguei minha casa, uma casinha lá no Zumbi e, depois, eu comecei a mexer com trem errado. Comecei a mexer com droga. Comecei a vender maconha, aí comecei a cheirar muito e aí foi nessa época que eu comecei a roubar e acabei sendo preso, com vinte e três anos eu fui preso. (...) Minha rotina era levantar de manhã, vender maconha, fumar bastante, comer eu comia num restaurante lá qualquer. Aí, logo na sequência, eu comecei a cheirar muito, que foi o que eu acabei de falar, aí comecei a roubar. (...) Separou e desandou tudo. (Trecho de entrevista concedida por Roberto, Piúma/ES, 06/02/19).

Eder, do grupo de controle, ressaltou que uma das principais mudanças pelas quais passou durante o período preso foi a perda da família, com o término de sua união estável e o afastamento do filho, tendo dito que "(...) ficava pensando o quê que eu ia fazer quando eu saísse de lá. Aí vem pensamento de raiva. Tal hora de tristeza, tal hora de culpa” (Trecho de entrevista concedida por Eder, Vitória/ES, 09/08/19).

Sem desconsiderar a existência da escolha e o poder da agência, o que nossa pesquisa indicou é a força e influência, para a interrupção criminal, de aspectos estruturais, do contexto e circunstâncias do entorno do agente, mais precisamente questões ligadas à existência de uma parceira afetiva e o nascimento/convívio com filhos.

\section{Considerações finais}

"Nada no mundo agora poderia tomar o lugar de minha esposa e filho na minha vida, pois eles significam tudo para mim...”, conclui Stanley na narrativa de sua difícil história de vida, repleta de desvios, crimes e prisões, relatada por Shaw (2013:182 [Tradução nossa]).

A pesquisa realizada permitiu perceber a estreita relação entre a interrupção criminal e o fortalecimento de vínculos familiares, em especial o convívio com a parceira e filhos. Em várias trajetórias envoltas em mudanças de rumo e recaídas, essas alterações nas ações empreendidas pelo agente coincidiam com mudanças nas dinâmicas familiares.

O convívio com uma parceira e o nascimento de filhos se mostrou, na maioria das trajetórias, como importantes pontos de inflexão na vida dos agentes, levando a significativas mudanças nos estilos de vida até então assumidos, constituindo-se uma maior integração em 
sistemas sociais, a exemplo da família, trabalho, igreja ou o serviço militar, um fator determinante para que o agente abandonasse, mesmo que temporariamente, a rotina de práticas ilícitas.

Sem desprezar o poder da agência e da escolha, que em alguma medida se encontra presente nessas mudanças de trajetórias, o que se percebeu na pesquisa realizada foi uma forte interferência de fatores situacionais e conjunturais, a partir de uma perspectiva interacionista.

Frequentemente se percebeu a desistência colateral, ou seja, em decorrência de variações no contexto de vida do agente, e menos como efeito de uma decisão refletida e ponderada sobre os ganhos e perdas do estilo de vida que vinha sendo levado.

Uma questão fundamental encontrada nos resultados desse estudo e que pode servir como referência aos demais estudos da área, trata-se de compreender a influência das famílias como fator de interrupção criminal, ou seja, se a família consegue, nos arranjos afetivos atuais, promover esta mudança diretamente, ou se a alteração comportamental motivada por questões familiares ocorre aliada a outros fatores, como a prisão.

Novas pesquisas podem, então, analisar a presença da parceira na vida dos envolvidos em situações ilícitas e se ela consegue, nos modos de convivência contemporâneos, promover esta mudança na forma como verificado outrora, ou se houve mudanças na dinâmica dos relacionamentos afetivos de maneira que a família interfere de forma mais significativa apenas quando o agente passa, por exemplo, pela experiência prisional e o sofrimento decorrente deste período.

Cabe enfatizar que em nosso trabalho todos os entrevistados tiveram uma experiência prisional e muitos indicaram a influência familiar para se afastar da vida de ilícitos, sendo certo que houve relatos desta interferência mesmo antes da prisão.

Entretanto, considerando que a maioria dos entrevistados relatou a influência da parceira e dos filhos na decisão de mudança de vida após a vivência de certo período no cárcere, novas pesquisas mais amplas, envolvendo relatos destas interrupções das práticas criminais influenciadas pela família independentemente de prisão em comparação com descrições de mudanças comportamentais relacionadas a interferências familiares em paralelo com a experiência no cárcere, podem ser úteis para permitir compreender o efetivo peso da família nas decisões de mudança de vida nos arranjos afetivos atuais, ou seja, se a companheira continua ostentando o mesmo relevante peso nesta decisão ou se houve perda na capacidade de ingerência familiar para promover a mudança discutida. 
De toda forma, independentemente de eventuais distinções na ênfase da interferência em ambas situações relatadas, o que nossa pesquisa permitiu perceber foi a importância da família, em especial da companheira e dos filhos, para a decisão de mudança de vida.

É certo, no entanto, que, assim como o envolvimento em ilícitos é multicausal, a interrupção criminal também decorre de motivos variados, sendo a interferência familiar um dentre outros relevantes fatores. Conforme Weber (2000), nenhuma interpretação de sentido pode pretender ser $a$ interpretação causal válida. Múltiplos fatores interferem em uma cadeia causal de práticas criminais e violentas, assim como na sua interrupção.

O que nossa pesquisa conseguiu indicar, a exemplo de outros trabalhos já realizados no campo da sociologia do controle social, é como o envolvimento em sistemas sociais, como a família, pode ter o condão de interferir em carreiras criminais, constituindo-se o casamento/ união estável e o nascimento de filhos em relevantes fatores aptos a ensejar mudanças de vida rumo a ações mais conformistas e de acordo com a moralidade dominante e os sistemas legais vigentes.

\section{Referências}

AGNEW, Robert (1991), “A Longitudinal Test of Social Control Theory and Delinquency". Journal of Research in Crime and Delinquency, v. 28, n. 2, pp. 126-156 [Consult. 05-02-2021]. Disponível em https://journals.sagepub.com/doi/10.1177/0022427891028002002

AGNEW, Robert (1992), "Foundation for a General Strain Theory of Crime and Delinquency". Criminology, v. 30, n. 1, pp. 47-87 [Consult. 05-02-2021]. Disponível em https://doi.org/10.1111/j.1745-9125.1992.tb01093.x

AGNEW, Robert (1993), "Why do They do It? An Examination of the Intervening Mechanisms between Social Control Variables and Delinquency". Journal of Research in Crime and Delinquency, v. 30, n. 3, pp. 245-266 [Consult. 05-02-2021]. Disponível em https://doi.org/10.1177/0022427893030003001

AGNEW, Robert; WHITE, Helene Raskin (1992), "An Empirical Test of General Strain Theory". Criminology, v. 30, n. 4, pp. 475-500 [Consult. 05-02-2021]. Disponível em https://doi.org/10.1111/j.1745-9125.1992.tb01113.x

BECKER, Howard (1964), "Personal Change in Adult Life". Sociometry, v. 27, n. 1, Mar. 1964, pp. 4053, [Consult. 23-03-2012]. Disponível em http://www.jstor.org/stable/2785801

FREITAS, Amilcar Cardoso Vilaça (2019), "Campos de possibilidade, liminaridade e deriva: trajetórias de adolescentes em conflito com a lei na Grande Vitória". DILEMAS: Revista de Estudos de Conflito e Controle Social, v. 12, n. 1, pp. 170-194 [Consult. 05-02-2021]. Disponível em https://revistas.ufrj.br/index.php/dilemas/article/view/16858/20931

GOFFMAN, Erving. A representação do eu na vida cotidiana; Petrópolis/RJ: Editora Vozes, 2014. 
HORNEY, Julie; OSGOOD, Donald Wayne; MARSHALL, Ineke Haen (1995), "Criminal Careers in the Short-term: Intra-individual Variability in Crime and its Relation to Local Life Circumstances". American Sociological Review, v. 60, n. 5, pp. 655-673 [Consult. 05-02-2021]. Disponível em https://doi.org/10.2307/2096316

JUNGER-TAS, Josine (1992), “An Empirical Test of Social Control Theory”. Journal of Quantitative Criminology, v. 8, p. 9-28 [Consult. 05-02-2021]. Disponível em https://doi.org/10.1007/BF01062757

LAUB, John; SAMPSON, Robert (2003), Shared beginnings, divergent lives: delinquent boys to age 70. Cambridge and London, Harvard University Press.

MATSUEDA, Ross L. (1982), "Testing Control Theory and Differential Association: a casual modeling approach”. American Sociological Review, v. 47, pp. 489-504 [Consult. 05-02-2021]. Disponível em https://doi.org/10.2307/2095194

PATERNOSTER, Raymond; MAZEROLLE, Paul (1994), "General Strain Theory and Delinquency: A Replication and Extension". Journal of Research in Crime and Delinquency, v. 31, n. 3, pp. 235-263. [Consult. 05-02-2021]. Disponível em https://doi.org/10.1177/0022427894031003001

POLAKOWSKI, Michael (1994), "Linking Self and Social Control with Deviance: illuminating the structure underlying a general theory of crime and its relation to deviant activity". Journal of Quantitative Criminology, v. 10, pp. 41-78 [Consult. 05-02-2021]. Disponível em https://doi.org/10.1007/BF02221008

SHAPLAND, Joanna; BOTTONS, Anthony (2017), "Desistance from crime and implications for offender rehabilitation" in, A. Liebling; S. Marunae; L. McAra (orgs.), The Oxford Handbook of Criminology. Oxford, The Oxford University Press, pp. 744-766.

SHAW, Clifford Robe (2013), The Jack-Roller: a delinquent boy's own story. Chicago, The University of Chicago Press.

WEBER, Max (2000), Economia e sociedade. Brasília, UNB. 


\begin{abstract}
The study aims to analyze findings that indicate the influence of strengthening family bonds, especially marriage / stable union and birth / living with children, to give up the practice of crimes, using semistructured interviews with prisoners convicted of property crimes or drug trafficking as a methodology. Using an interactionist perspective and working on the concepts of point of inflection and collateral withdrawal by Laub and Sampson (2003), the research carried out verifies how the greater integration in social systems such as the family favours the removal of illicit practices
\end{abstract}

Keywords: family; social control; withdrawal; crime.

\title{
Resumen
}

El presente estudio tiene el objetivo analizar los informes que indican la influencia del fortalecimiento de lazos familiares, específicamente, el matrimonio / unión estable y el nacimiento / el convivir con los niños, para la renuncia a la práctica de delitos. Este trabajo utiliza como metodología entrevistas semiestructuradas de presos condenados por delitos contra la propiedad o el tráfico de drogas. En este contexto, la perspectiva inter accionista y el uso los conceptos son un punto de inflexión y retiro colateral de Laub y Sampson (2003). En ese sentido, la investigación realizada verificó cómo una gran integración entre los sistemas sociales y/o el familiar favorecen la remoción de prácticas ilícitas.

Palabras clave: famíliar; el control social; la retirada; el crime. 